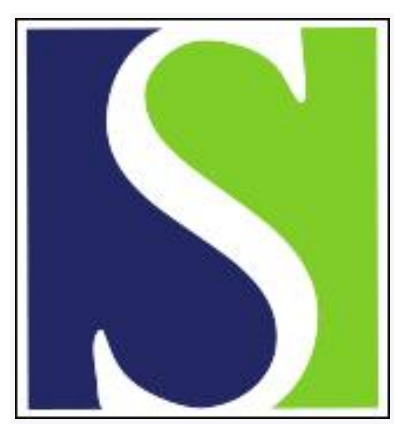

Scand J Work Environ Health 1981;7(2):73-83

https://doi.org/10.5271/sjweh.2560

Issue date: Jun 1981

\title{
Hazards of heat exposure. A review.
}

by Dukes-Dobos FN

Key terms: acute heat illness; cardiovascular disease; chronic heat illness; exposure; gastrointestinal disease; hazard; heat; heat exhaustion; heat exposure; heat stress; heat stress standard; heat stroke; mortality; permissible exposure limit to heat; review; steel worker; steel worker mortality; threshold limit value

This article in PubMed: www.ncbi.nlm.nih.gov/pubmed/7031869

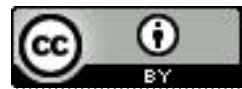




\title{
Hazards of heat exposure
}

\section{A review}

\author{
by Francis $\mathrm{N}$ Dukes-Dobos, MD
}

\begin{abstract}
DUKES-DOBOS FN. Hazards of heat exposure: A review. Scand $j$ work environ health 7 (1981) $73-83$. The usefulness of the various heat stress standards recommended by occupational health authorities in the United States is discussed from the point of view of their effectiveness in preventing acute heat illnesses. In this connection, the findings from an investigation of four recent fatal industrial heat casualties are described. A review is presented of the recent literature on acute occupational heat illnesses. Also reviewed is the information on chronic heat illnesses. Most of this latter data comes from studies performed in Europe and South America. However, a recent mortality study among steel workers in the United States contributed significantly to the knowledge of this problem area. This study found the primary targets of chronic heat illnesses to be the cardiovascular and the gastrointestinal systems, although there was some evidence that the reproductive functions may be affected. A discussion on how to prevent chronic heat illnesses is presented.
\end{abstract}

Key terms: acute heat illness, cardiovascular diseases, chronic heat illnesses, gastrointestinal diseases, heat exhaustion, heat stress standards, heat stroke, permissible exposure limits to heat, steel workers' mortality, threshold limit value for heat stress.

In common everyday speech the expression "heat stress" means that a person is exposed to excessive heat and, as a consequence, his or her health is adversely affected. This colloquialism is a source of confusion because in the scientific literature "heat stress" is synonymous with "heat load," which carries the connotation that adverse health effects will occur only if the heat stress exceeds the person's heat tolerance capacity. At lower levels of heat stress there is no risk of health damage, even though a person may feel discomfort. Ideally, it would be desirable tio eliminate heat stress completely by keeping the workplace at a comfortable temperature because the state of discomfort has many adverse behavioral effects, such as reduced work rate (10), increased irritability,

1 Division of Biomedical and Behavioral Science, National Institute for Occupational Safety and Health (NIOSH), Cincinnati, Ohio, United States.

Reprint requests to: Dr FN Dukes-Dobos, Robert Taft Laboratories C-22, 4676 Columbia Parkway, Cincinnati, OH 45226, USA. carelessness, and a feeling of fatigue (21). These effects may render a worker more prone to accidental injuries $(3,4)$. Unfortunately, the cost of keeping all job sites at comfortable temperatures is prohibitive.

The aim of the heat stress standards recommended or promulgated in different countries is limited to the prevention of acute heat illnesses which result from exposure to heat stress beyond human tolerance. This is true also for two of the heat stress standards recommended in the United States, lie, for the one recommended in 1974 by the ad hoc Standards Advisory Committee for Heat Stress of the Occupational Safety and Health Administration (OSHA) (20) and the threshold limit value (TLV) of the American Conference of Governmental Industrial Hygienists (ACGIH) (1), first published in 1973. An exception is the heat stress standard recommended by the National Institute for Occupational Safety and Health (NIOSH) (19), which limits the exposure time to heat in joibs where unimpaired mental performance is critical from the point of 
view of safety. Unfortunately there are no data available at this time for determining the effectiveness of these exposure time limits in reducing the number of accidents. To answer the questition of whether these two recommended standards $(19,20)$ and the TLV (1) would be effective in preventing acute illnesses, I have examined the prevailing circumstances in four recent cases of fatal heat stroke and one case of heat exhaustion which occurred in different industries. From this analysis it is possible to draw some conclusions about the usefulness of the preventive measures contained in the aforementioned documents.

The prevention of chronic heat illnesses due to long-term work in hat environments has not been addressed in the recommended standards $(19,20)$ and the TLV (1): because of the scarceness of data on the health effects of exposures to low-level heat stress over different periods of time. In this paper, however, the pertinent literature on the health effects of chronic heat illnesses is also reviewed, including a recent mortality study performed in the steel industry (23).

\section{Acute heat illnesses}

The causes of acute heat illnesses (table 1) are well established and have been described in detail by Leithead \& Lind (16). What is still not known for certain is why one worker suffers from a heat cramp, another collapses of heat exhaustion, while still another is able to continue to work in the same job as the other two without apparent ill effect, and then succumb to heat stroke when exposed to heat beyond tolerance levels. It can be assumed that much depends on the worker's inherent and acquired physical fitness and heat tolerance, as well as on food and fluid intake. For instance, if a person's cardiovascular capacity is low, there is an increased probability that heat exhaustion and collapse may ensue before the body heats to the point at which heat stroke is triggered. This situation may actually benefit that person because one can easily recover from heal exhaustion if allowed to rest in a cool place and drink cool liquids, while heat stroke is fatal if wholebody cooling (30) is not initiated early in the incipient stage of the disease. Similarly, a person may become incapacitated by muscle cramps due to incomplete replacement of the salt lost in sweat (17). This person, however, will recover soon after resting in a cool place and drinking a glass of saline soluttion, while anolther, whose salt and water intake was saltisfactory, will continue to work and later may become the victim of a more serious heat illness.

On the other hand, a mild heat illness, if not properly treated, can lead to a more serious one. For instance, a person who collapses from heat exhaustion and is not taken out of the hot enviranment before becoming overheated may develop a heat stroke as well. Similarly, salit depletion makes one more susceptible to either heat exhaustion or heat stroke (15). Furthermore, if workers become dehydrated beyond $1.5 \%$ of their total body weight,

Table 1. Causes of acute heat illnesses.

Name of heat illness and synonyms

Causal factors

\section{Heat cramp}

Heat exhaustion, heat prostration, heat syncope

Heat stroke, sun stroke

$\left.\begin{array}{l}\text { Skin diseases } \\ \text { Prickly heat } \\ \text { Heat rash } \\ \text { Anhidrosis }\end{array}\right\}$

Salt $(\mathrm{NaCl})$ depletion, water and electrolyte imbalance

Salt depletion with or without dehydration, resulting in hypovolemia and/or cardiovascular insufficiency

Hyperthermia resulting in cellular damage in different organs of the body

Reduced resistance of the skin due to constant wetting

Obstruction of sweat gland ducts by keratin debris; inflammatory reaction due to irritants or infection

Excessive vasodilation in the skin

Insufficient replacement of water lost by sweating 
due to drinking less fluild than necessary for replacing the water lost by sweating, not only will their physical and mental fitness deteriorate, but they also become more susceptible to acute heat illnesses and accidents (6). Finally, during work in a very hot and humid environment, the worker's skin will be constantly soaked by sweait. Those who have sensitive skin or do not take a shower after work regularly or live in the tropies where the nights are also hot and humid may develop heat rash, also called prickly heat. This condition causes the ducts of the sweat glanids to become clogged, thus interfering with sweating. Workers suffering from this condition are highly susceptible to other acute heat illnesses because they have lost their most effective mechanism for eliminating hear from their body, ie, evaporating sweat from the skin surface.

From the foregoing presentation it is apparent that if the workers in a hot plant often suffer mild heat illnesses, the situation should not be dismissed as a harmless condition. Unfortunately, not every worker employed in hot jobs nor their supervisors are aware of these acute heat illnesses, how to prevent them, how to recognize them, and how to give first aid. Sometimes even physicians may have difficulty in differentiating between heat exhaustion and heat stroke in their early stages if the victim's body temperature is relatively low (33). Although a rectal temperature of $40.6^{\circ} \mathrm{C}$ is considered to be the trigger point for an incipient heat stroke (11), a few lethal heat stroke cases have been described in the literature in which the patient's rectal temperature on admission to the hospital was as low as $36.6^{\circ} \mathrm{C}$ (8). Of course, one cannot be sure how much time elapsed between the paitient's last heat exposure and the arrival at the hospital and how much cooling was supplied to the victim before the rectal temperature was measured.

Recently, Bartley (2) analyzed 24 cases of heat stroke which occurred among soldiers of the US Army between 1972 and 1975 . He came to the conclusion that the multiplicity of host and environmental factors which interact in the causation of heat stroke make it doubtful whether total prevention can ever be attiained under operational conditions of military training, sports, and certain occupations. Bartley based this statement on a study of heat stroke cases which occurred in the US Army; thus it is in order to examine whether the generalization he made in his conclusion, in particular the field of occupational heat stress, is valid.

In 1977 and 1978, NIOSH was involved in exploring the circumstances surrounding four cases of fatal occupational heat stroke and one case of heat exhaustion. In two of the heat stroke cases, NIOSH scientists performed a field survey a few weeks after the casuality. They measured the environmental heal prevailing at the job siltes where the heat casualities occurred and assessed the metabolic heat load of workers who performed the same activities as the heat stroke victims. In the remaining three cases, data on the viictim's heat exposure and other prevailing circumstances were obtained from OSHA inspectors.

The analysis of these data showed that the same environmental and host factors thait make it difficult to prevent heat strokes in the Army were also present in these industries. The most dangerous environmental factor is a sudden heat wave which finds the soldiers, as well as the workers, unacclimatized to this unusually high theat stress. However, for industrial application the aforementioned recommended theat stress standards $(19,20)$ list some preventive practices which can be used in situations in which acclimatization procedures cannot be implemented. For instance, in industry it is possible to add some relief workers to the work force and increase the duration or number of rest periods; one can also reduce the heat load by protective clothing, mechanization, automation, and available climate-controlled rest places. Thus, as far as environmental heat is concerned, occupational heat casualties seem to be preventable by proper advance planning. As a matter of fact, Bartley himself suggests later in his paper (2) that even in the military better planning for hot weather conditions can significantly reduce the number and severity of heat casualties.

Still, all these preventive measures do not address the problem of the host factors which, according to Bartley (2), are partly responsible for heat fatalities. To eliminate the susceptible individuals, the Army applies medical screening of recruits. Sim- 
ilarly, the recommended heat stress standards $(19,20)$ contain requirements for preemployment and periodic medical examinations. Is is suggested in the NIOSH criteria document for heat stress (19) that individuals who belong to the high risk group, such as the obese, the alcoholic, and the chronically ill, should not be placed in jobs with high heat stress. Furthermore, workers and supervisors should be informed about the conditions that make one more prone to heat illnesses such as dehydration, fatigue, lack of sleep, acute or chronic illnesses, and overeating.

Table 2 shows some of the host factors of the five warkers whose heat casualties were analyzed. The first four cases relate to fatal heat strokes, and the fifth is a case of heat exhaustion with collapse. In three oult of the five cases the workers were acclimatized to work in heat; however, since all the cases occurred during a heat spell, one must assume that none of them were completely acclimatized to the prevailing heat stress on the day they became ill. In addition, each of the five workens had one or more negative condition in their medical history or in their physical fitness which may have reduced their heat tolerance. These data make it highly probable that hosit factors played an important role in the causation of the five heat illnesses. However, the presence of contributory host factors does not necessarilly support the thesis of inevitabilility of acute heat illnesses. Perhaps a more stringent medical screening of workers being placed in hot jobs and closer medical monitoring of workers employed for many years in hot jobs could have prevented the occurrence of these acute heat illnesses.

As to the fatal outcome of the heat stroke cases, some interesting facts were discovered. In three cases the workers did nat collapse on the job. One was dressed to go home and collapsed near the exit, another collapsed on the way to the company's parking lot, and a third drove away in his car and collapsed at a nearby gas station. All three of the workers felt ill already before they left work, but nobody recognized that they were in the state of impending theat stroke. One cannolt but wonder whether the lives of these workers could have been saved if the requirements of the recommended heat stress standards $(19,20)$ had been adhered to; specifically in regard to the training of workers in hot plants on how to recognize acute heat illness and how to give first aid.

Another significant finding was that at the plants where the fatal heat casualties occurred, numerous milder heat illnesses had been itreated in the dispensaries during the same summer. Some of these heat illnesses were not identified as such, but were reconded in other disease categories. This raises the question, "How many heat illnesses go unreported?" Ellis (7) reviewed the causes of excess deaths occurring in summer heat spells and found a great increase in montality during these periods.

Table 2. Host factors identified for five heat casualties.

\begin{tabular}{|c|c|c|c|c|c|}
\hline Case & $\begin{array}{l}\text { Acclima- } \\
\text { tization }\end{array}$ & Medical history & Physical fitness & $\begin{array}{l}\operatorname{Age}(a) / \\
\text { sex }\end{array}$ & Work history \\
\hline 1 & $\begin{array}{l}\text { Acclima- } \\
\text { tized }\end{array}$ & $\begin{array}{l}\text { Impaired hearing and } \\
\text { speech }\end{array}$ & $\begin{array}{l}\text { Overweight, probably } \\
\text { dehydrated }\end{array}$ & $21 / \mathrm{male}$ & - \\
\hline 2 & $\begin{array}{l}\text { 2nd day } \\
\text { on hot job }\end{array}$ & $\begin{array}{l}\text { Just returned from } \\
\text { alcohol withdrawal } \\
\text { treatment }\end{array}$ & Slightly overweight & $21 / \mathrm{male}$ & - \\
\hline 3 & $\begin{array}{l}\text { Acclima- } \\
\text { tized }\end{array}$ & $\begin{array}{l}\text { Had a recognized } \\
\text { alcohol problem }\end{array}$ & $\begin{array}{l}\text { Was not under the } \\
\text { influence }\end{array}$ & $52 / \mathrm{male}$ & $\begin{array}{l}\text { Employed } 24 \text { a in hot } \\
\text { plant }\end{array}$ \\
\hline 4 & $\begin{array}{l}\text { Acclima- } \\
\text { tized }\end{array}$ & $\begin{array}{l}\text { Rheumatoid arthritis, } \\
\text { cleared for work by } \\
\text { factory dispensary }\end{array}$ & $\begin{array}{l}\text { Returned to work } 25 \\
\text { weeks before after } \\
15 \text { months sick, } \\
\text { overweight }\end{array}$ & $56 /$ male & $\begin{array}{l}\text { Employed } 24 \text { a in hot } \\
\text { plant }\end{array}$ \\
\hline 5 & $\begin{array}{l}\text { 2nd day } \\
\text { on hot job }\end{array}$ & $\begin{array}{l}\text { Hemorrhoid operation } \\
10 \mathrm{~d} \text { before }\end{array}$ & $\begin{array}{l}\text { Heat exhaustion on } \\
\text { previous day, cleared } \\
\text { by nurse for work }\end{array}$ & $\begin{array}{l}\text { Late } 20 \mathrm{~s} \\
\text { (estimated)/ } \\
\text { male }\end{array}$ & $\begin{array}{l}\text { Employed in same } \\
\text { plant for } 15 \text { months, } \\
\text { but not in hot job }\end{array}$ \\
\hline
\end{tabular}


He also observed that, in addition to a large increase in fatal heat strokes, about ten times more people are listed as dying from diseases other than from heat stroke itself. These diseases include arteriosclerotic and degenerative heart diseases, cerebrovascular accidents, diabetes, and genitourinary diseases, and they are probably aggrevated by the excessive environmenital heat. However, death certificates rarely include information on contributory causal factors; thus the magnitude of the death toll taken by the heat waves is much greater than reported officially.

Bartley (2) may be right, at leasit for the present, that all heat stroke fatalities of accupational origin cannot be prevented. However, based on the detailed analysis of the few cases described in this report, the number of cases could probably be greatly reduced with more stringent compliance to the preventive measures recommended in the standards $(19,20)$.

In September 1979 I convened a workshop meeting under the aegis of NIOSH (proceedings in press) to explore whether recent accrued knowledge would make it possible to modify the recommended heat stress standand (19) for the purpose of making compliance, as well as enforcement, simpler without reducing its efficacy. The participants of this workshop recommended that the heat stress standard should give more flexibility to management in determining what preventive measures to use. However, they also recommended that preplacement and periodic medical examinations of workers in hot jobs should be mandatory. Furthermore, it was agreed that the standard should require that each industry which operates hot plants put in writing the policies and practices they adopt for preventing heat illnesses. This way the OSHA inspector could easily determine whether the policies and practices are acceptable and whether they are adhered to in practice.

A number of problems could not be resolved at the workshop. Outstanding among them was the level of heat stress above which a job must be considered a hat job from the point of view of compliance requirements. The workshop participants stipulated however that a level identified as the "action level" should be set below the ACGIH TLV (1); it should be low enough to assure that none of the workers exposed to these conditions will risk becoming a victim of heat illness, not even unacclimatized workers. They also recommended that another level of heat stress should be set above the ACGIH TLV (1) as a maximum permissible exposure level. They recognized that, in order to establish these levels of heat exposure, more research is necessary, and a lisit of research recommendations was developed at the workshop.

One of the recommended research topics deals with a very important aspect of the prevention of acute heat illnesses, namely, to find the relationship between deep-body temperature and the risk of heat illnesses. The guiding principle of the recommended heat stress standards, as well as the TLV $(1,19,20)$, is that the workers' deep-body temperature should mot be permitted to exceed $38^{\circ} \mathrm{C}$. This principle is based on the recommendation of a World Health Organization (WHO) scientific group report (31). Some participants of the recent NIOSH workshop suggested that this $38^{\circ} \mathrm{C}$ limit should not be interpreted as an absolute maximum permissible deep-body temperature. They felt that fluctuations during the day may go up to $39^{\circ} \mathrm{C}$ without the individual being under undue strain as long as the 8-h time-weightred average does not exceed $38^{\circ} \mathrm{C}$. Scientists of the South African Chamber of Mines base their permissible limits on accurate statistics on the number of heat strokes occurring among miners. Stewart reported (Second International Mine Ventilation Congress, Reno, NV, 1979) that they acclimatized 350,000 gold miners in their climatic chambers annually in Souh Africa. This large worker population is very suited for epidemiologic studies. As a criterion for reducing the workshift time to $6 \mathrm{~h}$, Wyndham et al (34) used 1:100 probability that the miners' rectal temperature reaches $38.6^{\circ} \mathrm{C}$. For a "stop-work" limit he used as a criterion the $1: 2,000$ probability of the miners' rectal temperature reaching $39.2^{\circ} \mathrm{C}$. Stewart (27) recentily suggested that the permissible exposure limits for miners be based on a $1: 1,000,000$ risk that the fourth hour rectal temperature of a nude acclimatized miner will exceed $40^{\circ} \mathrm{C}$. It is interesting to note that recently he also estimated (Second International Mine Ventilation Congress, Reno, NV, 1979) that the ACGIH TLV values correspond roughly with con- 
ditions carrying a $1: 1,000,000$ risk that $u n-$ acclimatized men will reach a $40^{\circ} \mathrm{C}$ rectal temperature in the fourth hour of the workshift. However, according to Strydom (28), the South African data cannot be adopted to US conditions because of differences in social, cultural, and nutritional factors. Goldman (9) observed that when the mean skin temperature of clothed men increased beyond $36^{\circ} \mathrm{C}$, a rectal tem-

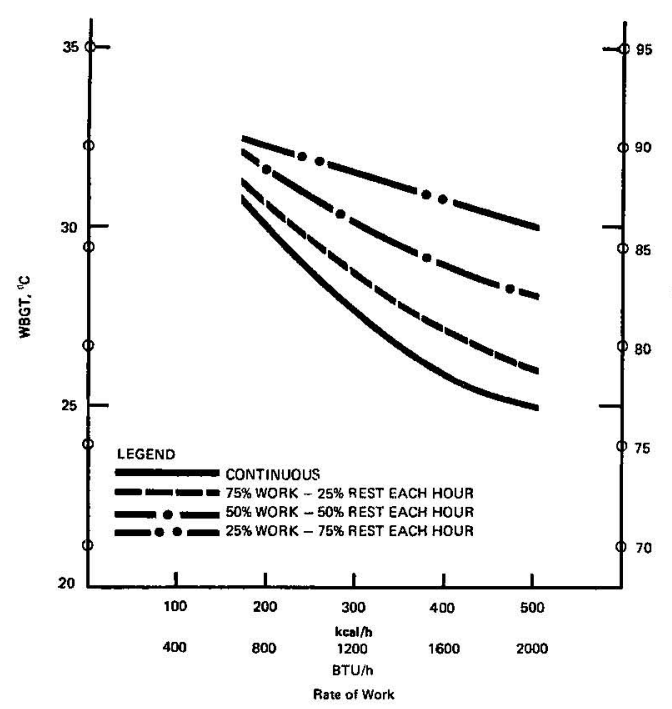

Fig 1. Permissible heat exposure threshold limit value. $(\mathrm{BTU}=$ British thermal units, WBGT $=$ wet bulb globe temperature) perature of $39.2^{\circ} \mathrm{C}$ induced about $10 \%$ frank heat exhaustion collapses, a value which translates into an estimated risk of $25 \%$. At this stage even a small further increase in redtal temperature can raise the risk of heat collapse subsitantially. For instance, if rectal temperature reaches $39.5^{\circ} \mathrm{C}$, the risk increases to $50 \%$. However, these data were obtained on young and physically fit military personnel; thus they also cannot be considered valid for industrial workers in general. Indeed, the question of maximum permissible deepbody temperature cannot be decided until the research work suggested by the participants of the recent NIOSH workshop has been finished. Meanwhile, close adherence to the recommended heat stress standards and/or $\operatorname{TLV}(1,19,20)$ remains the best way to prevent acute heat illnesses. The ACGIH TLV and the preventive work practices recommended in these standards are shown in fig 1 and table 3 .

\section{Chronic heat illnesses}

In contrast to acute heat illnesses, chronic heat illnesses have not been reviewed in the literature in a systematic way. An attempit will be made to give a concise overview of relevant publications and

Table 3. Work practices for hot jobs as recommended by the Standard Advisory Committee on Heat Stress of the Occupational Safety and Health Administration.

Compulsory work practices for all hot jobs

1. Adequate water supply

2. Acclimatization

3. First-aid training

4. Training of workers for health and safety procedures and work practices

5. In case of heat illness, the WBGT a must be assessed on the site
Special work practices for hot jobs $b$

1. Engineering controls

2. Work-rest regimen

3. Additional acclimatization

4. Adaptive work scheduling

5. Protective clothing and/or equipment

6. Freedom to interrupt work during extreme discomfort
Work practices required for extreme heat exposure only

1. Duration of exposure time regulated by experienced workers' judgement (freedom to interrupt work during extreme discomfort)

2. Preplacement and periodic medical examination (also required in any hot job if work load is heavy)

3. Observation by trained supervisor

4. Protective clothing (mandatory)

a WBGT $=$ wet bulb globe temperature.

b Only one mandatory if environmental and work intensity is monitored; more than one mandatory when no monitoring is done. 
classify the chronic heat illnesses according to their etiology. There are at least three types of chronic heat illnesses. Type I consists of the aftereffects of acute heat illnesses (table 4); those belonging to type II are brought about by working in excessive hat jabs for a few weeks, for a few months, for years, or perhaps as long as one's working liffetime (table 5); those belonging to type III occur only among people living in climatically hot regions of the world (table 6).

Chronic, type I heat illnesses (table 4) may not be diagnosed as clear-cut disease conditions; however, it has been well established that a person who has once suffered an acute heat illness (except heat cramp) has a reduced heat tolerance for some time thereafter, perhaps for the rest of his/her life (16). After a heat rash this phenomenon may be due only to reduced sweating capacity; however, after a heat stroke it may be the consequence of irreversible cell damage in the brain, liver, kidneys, and other organs of the body (33). The severity of the cellular damage largely depends on the severity of the heat stroke, particularly on the length of hyperthermia and on the maximum deep-body temperature reached.

Chronic, type II heat illnesses (table 5) are the result of long-term exposure to work in heat. It is not quite clear whether the symptoms observed clinically and the abnormalities found by medically screening worker populations are part of one and the same heat iliness or whether different chronic heat illnesses may develop depending on the severity and length of exposure. Alternatively, it is possible that the same heat stress may trigger different illnesses in different persons and may depend on the constitutional factors and the medical history of the individual. Schwartz (26) observed an illness among workens in hot jobs which occurred several months after their employment. This illness was characterized by the set of symptoms shown in table 5 . These workers were acclimatized to healt but were not accustomed to the heavy physical demands of the job; they were ambitious individuals who would not give up their jobs in spite of the strain they were experiencing. As a consequence, their symptoms gradually became worse, and, if these workers were not removed from these strenuous jobs, sooner or later they suffered irreversible cardiovascular damage.

Schwartz (26) did nat present case histories in his paper, nor did he describe the results of clinical laboratory tests. Most of the symptoms he found were not specific to heat stress and had also been observed

Table 4. Chronic heat illnesses - Type I, aftereffects of acute heat illnesses.

\begin{tabular}{|c|c|}
\hline Acute illnesses & Chronic aftereffects \\
\hline $\begin{array}{l}\text { Prickly heat, } \\
\text { heat rash }\end{array}$ & $\begin{array}{l}\text { Reduced heat tolerance; dis- } \\
\text { function of sweat glands; re- } \\
\text { duced sweating capacity }\end{array}$ \\
\hline Heat cramp & $\begin{array}{l}\text { Reduced heat tolerance; } \\
\text { muscle soreness, stiffness; } \\
\text { reduced mobility }\end{array}$ \\
\hline Heat exhaustion & $\begin{array}{l}\text { Reduced heat tolerance; } \\
\text { chronic heat exhaustion (see } \\
\text { table 5) }\end{array}$ \\
\hline Heat stroke & $\begin{array}{l}\text { Reduced heat tolerance; cel- } \\
\text { lular damage in different or- } \\
\text { gans, particularly in the } \\
\text { central nervous system, heart, } \\
\text { kidneys, and liver }\end{array}$ \\
\hline
\end{tabular}

Table 5. Chronic heat illnesses - Type II, cumulative effects of long-term exposure.

\begin{tabular}{|c|c|}
\hline $\begin{array}{l}\text { After several months } \\
\text { in a hot job }\end{array}$ & $\begin{array}{l}\text { After many years } \\
\text { in a hot job }\end{array}$ \\
\hline $\begin{array}{l}\text { Chronic heat } \\
\text { exhaustion } \\
\text { Symptoms } \\
\text { Headache } \\
\text { Gastric pain } \\
\text { Sleep disturbance } \\
\text { Irritability } \\
\text { Tachycardia } \\
\text { Vertigo } \\
\text { Nausea }\end{array}$ & $\begin{array}{l}\text { Hypertension } \\
\text { Reduced libido } \\
\text { Sexual impotency } \\
\text { Myocardial damage } \\
\text { Nonmalignant diseases } \\
\text { of the digestive organs } \\
\text { Hypochromemia }\end{array}$ \\
\hline
\end{tabular}

Table 6. Chronic heat illnesses - Type III, effects of residence in climatically hot regions.

\begin{tabular}{|c|c|}
\hline Tropics & Desert \\
\hline $\begin{array}{l}\text { Frequent skin diseases } \\
\text { Sleep disturbance } \\
\text { Susceptibility to minor injuries } \\
\text { and sickness } \\
\text { Psychoneurosis (tropical } \\
\text { lethargy) } \\
\text { Anhidrotic heat exhaustion }\end{array}$ & $\begin{array}{l}\text { Kidney stones } \\
\text { Anhidrotic heat } \\
\text { exhaustion }\end{array}$ \\
\hline
\end{tabular}


in the state of chronic fatigue without heat exposure. However, a general feeling of weakness, irritability, vertigo, and nausea has been observed (5) in the Hungarian steel industry during the hottest parts of the summer, among the workers whose sweat rate reached 7 to 9 1/8-h workshift during a heat spell lasting $5-10 \mathrm{~d}$. The workers' urinary chlorine concentration before and iduring the workshift was practically zero during this period and therefore showed the extreme effort exerted by their electrolyte regulaiting mechanism. The symptoms described by Schwartz (26) thus could have been, at least partially, due to a chronic form of salt depletion heat exhaustion.

Apparenitly, the level of heat stress to which these workers must have been exposed is below the heat stress which would cause an acute heat illness, but it is beyond the level called the "chronic heat tolerance limit" (CHTL). This limit was found (5) to be, in terms of sweat rate, $51 / 8-h$ workshift for the average acclimatized worker. It is based on the assumption that the daily salt intake of a worker is about 5-6 g during the workshifit and $7-\mathbf{8} \mathrm{g}$ during the rest of the day. Whether the CHTL can be increased to higher levels, if the salt intake is increased during the workshift, is one of the questions which cannot be answered without further research. It has been postulated that increased salt intake may cause poltassium depletion from the muscle cells and, thus reduce muscular strength and physical performance capacity (28).

Another problem of increased salit intake is related to its effect on blood pressure. Kloetzel et al (13) screened the 350 employees of a Brazilian steel plant for blood pressure. He found that the proportion of mild and severe hypertensives (above 18.67/ 21.33 and above $21.33 / 12.67 \mathrm{kPa}$ ) was signicantly higher among the 186 workers of the blast furnace, open hearth, and rolling mills operations who were exposed regularly to high heat stress. The prevalence of severe hypertension was greatest $(30 \%)$ among the workers employed in these jobs for as long as 20 to 29 a, whereas among those employed from 0 to 4 a, the prevalence was only about $7 \%$. This relathionship ibetween an increase in prevalence with time spent on the job occurred in spite of the fact that many workers were laid off at an earlier age because of hypertensive cardilovascular disease. Therefore few of the workers reached the legal retirement span of 35 a of work. Kloetzel et al (13) considered these findings tentative because they felt that a better controlled study would be necessary to confirm these preliminary findings. However, they presented evidence that the observed excess of hypertension among the workers exposed to intense heat was not due to an uneven age or racial composition of the cohort or to excessive salt intake. As a matter of fact, even though salt dispensers were available in the plant, the workers avoided them lbecause of the rumor that the salt tablets might be responsible for impatency.

This latter observation brings into focus two major health problems connected with long-term employment in hat jobs. One health problem is related to the fact that hypertensive patien'ts must be kept on a low sodium diet which requires low salt intake. This situation confronts the hypertensive workers of hat plants with a dilemma: if they reduce their salt intake, they may become more susceptible to acute or chronic heat exhaustion and heat cramps; if they maintain or increase their salt intake, they may aggravate their hypertension. In addition, if workers of a hot plant are treated with diuretics - the medication of choice for certain types of hypertension - they will be at a disadvantage as far as heait tolerance is concerned because they are already slightly dehydrated even before they start to sweat. As a matter of fact, experiments performed on spontaneously hypertensive rats in our laboratories by Wright et al (32) showed that hypertension per se may reduce heat tolerance significantly.

This health problem has already been recognized by some physicians who became aware of the fact that several of their hypertensive patients are exposed to intense heat on the job. They try to compensate for this fact by prescribing a lower dose of diuretics during the summer. However, this is hardly a satisfactory solution to the problem. It has to be established by systematic research how much heat tolerance is lost at different stages of hypertension and with different regimens of treatment. Furthermore, it thas to be determined exactly how much heat stress, 
over how long a period of time, will make workers more susceptible to hypertensive candioviascular disease. The value of the CHTL has to be set according to a level which is safe for hypertensive individuals. The only other alternative would be to exclude hypertensive workers from hoit jobs by preemployment and periodic medical examinations.

The other health problem referred to in the paper of Kloetzel et al (13) is the fact that the workers in hot jobs are concerned about their sexual potency. Allthough these workers blamed the salt tablets for their impotency, it is more probable that the heat stress to which they are exposed is culpable for their sexual deficiency. I have often heard complaints of reduced libido when talking to workers in hot shops, but is was not clear which of the many stress factors present in these jobs should be suspected of being responsible for this phenomenon. However, Knecht et al (14) recently examined, in our laboratory, the effect of heat stress on the reproductive functions of male and female ralts. They observed that daily exposure of the male rat for $55 \mathrm{~min}$ at $38.2^{\circ} \mathrm{C}$ decreased copulation and reduced the rate of conception. The same exposure of females caused disruption of their estrous cycle until they became acclimatized to heat. Both male and female exposure to this short but intense heat on a daily basis adversely affected the survival of the fetus. During lactation the females' heat tolerance decreased signifificantly and resulted in increased mortality due to heat stroke. The results of these animal experiments cannot be directly extrapolated to man; however, it is quite possible that future research on human subjects will reveal that the reproductive functions are very sensitive to heat stress and therefore should play an important role in determining the level of the CHTL.

Other chronic health effects observed among workers employed in hot jobs (table 5) suggest that just as in the state of chronic heat exhaustion which develops after a few months on the job (26), it is the cardiovascular system which is the most affected by many years of employment in hot jobs. Kenedi (12) found pathological electrocardiograms four times as frequently among Hungarian foundry workers exposed to intense heat than among those ex- posed to moderate heat. Mayer-Theveniaud (18) found a higher incidence of cardiac conduction anomalies among French workers in hot jobs. At the 7th Congress of the International Ergonomics Association (Warsaw, Poland, 1979) Kieč reported that the 217 foundry workers who perform the hottest jobs in the Lenin Steel Works had the worst hemodynamic parameters as determined by polycardiography. He emphasized that this group of workers was highly self-selected, physically the most fit, strongest and healthiest in view of other clinical parameters. He postulated that the deterioration of hemodynamic parameters was due to myocardial damage sustained during the short periods of heavy work under extremely high heait exposures, when the heart rates of the workers reached their maximum. If further research confirms this postulate, it should have significant impact on what exposure limits to recommend in a heat stress standard. At present, action levels and exposure limits in both of the recommended standards $(19,20)$ and the ACGIH TLV (1) are expressed in terms of time-weighted averages. If Kieč's conclusions are verified by future research, then it becomes imperative to include limiting levels for peak exposures in the heat stress standards, even if such exposures occur only for a short period, 1 or 2 min, each workshift.

There is some evidence that, in addition to the cardiovascular system, the digestive organs are also affected by long-term exposure to heat. Redmond e't al (23) performed a mortality study under a NIOSH contract, for which I served as project director. The study cohort consisted of steel workers employed in large foundries located in Allegheny County, PA. The only diseases more frequent than cardiovascular disease as the cause of death among workers exposed to intense heat were the nonmalignant digestive diseases. One possible explanation for this finding is that physiological adaptation to heat involves peripheral vasodilation and a compensatory vasoconstriction in the splanchnic digestive organs. When this condition prevails day-after-day for many years, it can cause a reduced functional capacity and a lowered resistance to disease. Indeed, Rowell et al (25) found evidence of hepatic-splanchnic hypoxia in subjects exposed to heavy exercise at an environ- 
mental temperature of $48.9^{\circ} \mathrm{C}$. Experiments performed in our laboratories by Torasson et al (29) showed a decrease of mucosal tissue and a decreased rate of glucose metabolism in the initestines of heat-exposed rats. Furthermore, in a personal communication, FM Spiach reported a decrease in the level of hemoglobin among workers exposed to intense heat in some Polish siteel plants. Although there can be several possible causes for this disorder, at least three of them are connected with disorders of the digestive organs: occult bleeding from the intestines, atrophy of the gastric mucosa, and hypoxia of the liver.

More research is needed to determine the intensity and length of heat exposure which will result in gastrointestinal disorders. However, Redmond's study (24) presents good information about the yearround environmental and metabolic heat load of the jobs in which the members of the cohort were employed. It is interesting to note that a significantly high risk for digestive diseases (excluding cirrhosis of the liver) was found among persons who had ever worked in jobs above the ACGIH TLV (1). In addition, those who worked in jobs below the TLV for 15 a or longer also had increased mortality due to digestive diseases. These findings suggest that the values of a CHTL must be set lower than the current TLV if disorders of the digestive organs are to be prevented among workers employed in hot jobs for 15 a or more.

It is interesting to note that the study cohort of Redmond et al (24) did not show an increased mortality due to cardiovascular diseases, except for those workers employed less than six months in hot jobs. This finding suggests that, by way of natural selection, workers with low cardiovascular fitness do not stay longer than six months in the hot jobs of these steel plants. Those remaining in the hot jobs for more than six moniths apparently have a better than average cardiovascular fitness, and, in fact, their mortality due to cardiovascular diseases was less than that of the reference group.

Table 6 shows the symptoms of chronic heat illnesses which have been observed among residents of climatically hot regions. A concise review of disorders observed in people who moved from tem- perate regions to tropical zones has been presented by Pepler (22). He leaves the question open of whether heat stress in the hat and humid tropics causes different symptoms than when the exposure to similar environments is limited tho the workplace. He suggests that cultural, social, and hygienic factors may play a greater roll in tropical neurasthenia than climatic stress. Accordingly, its prevention is best achieved by psychological methods, although initroduction of air conditioning can go a long way.

Anhildratic heat exhaustion, as described by Leithead \& Lind (16), seems to be a condition limited to the military personnel stationed in either tropical- or desert-type climatic regions. It usually occurs after about a four to seven months' stay in these hot locations. However it is not quilte clear whether it is a separate disease entity or just a chronic and more severe form of prickly heat, occasionally combined with chronic heat exhaustion.

A high incidence of kidney stones among residents of desert regions has been mentioned by several investigators $(14,15)$ and is considered to be a consequence of adaptation to inaidequate water consumption, which results in highly concentrated urine. Workers in the desert regions do not realize how much they are sweating because the sweat evaporates immediately from their skin due to the dryness of the air. They should be encouraged to drink more water than they would spontaneously.

\section{Acknowledgments}

I wish to express my appreciation to $\mathrm{Mr} \mathrm{R}$ James and Mr W Carlson for performing the fiield studies at the job sites where the heat casualties occurred, to Drs A Henschel and $\mathrm{B}$ Johnson for reviewing the manuscript, and to Ms M Swenk for secretarial assistance and typing.

\section{References}

1. American Conference for Governmental Industrial Hygienists. Threshold limit values for chemical substances in workroom air adopted by ACGIH for 1979. Cincinnati, $\mathrm{OH} 1979$.

2. Bartley DB. Heat stroke: Is total prevention possible? Mil med 142 (1977) 528-535. 
3. Belding HS, Hatch TF, Hertig BA, Riedesel MIL. Recent developments in understanding of effects of exposure to heat. In: Proceedings 13th international congress on occupational health. New York, NY 1960. Book Craftsmen Associated, New York, NY 1961.

4. Brouha L. Physiology in industry. Pergemon Press, New York, NY 1960.

5. Dobos F, Hamar N, Tarjan N. Adaequater und minimaler Kochsalzbedarf in der Hitzearbeit, unter besonderer Beruecksichtiqung der Hitzearbeiter in der ungarischen Eisen- und Stahlindustrie. Acta med acad sci hung 6 (1954) 433-451.

6. Dukes-Dobos FN. Rationale and provisions of the work practices standard for work in hot environments as recommended by NIOSH. In: Horvath SM, Jensen RC, ed. Standards for occupational exposures to hot environments. Department of Health Education and Welfare, Cincinnati, $\mathrm{OH}$ 1976, pp 27-42. (HEW publication number (NIOSH) $76-100$ ).

7. Ellis FP. Mortality from heat illness and heat aggravated illness in the United States. Environ res 5 (1972) $1-58$.

8. Gauss H, Meyer KA. Heat stroke: Report of one hundred and fifty-eight cases from Cook County Hospital, Chicago. Am j med 154 (1917) 554-564.

9. Goldman RF. Prediction of human heat tolerance. In: Folinsbee LJ, Wagner JA, Borgia JF, Drinkwater BL, Gliner JA, Bedi JF, ed. Environmental stress. Academic Press, New York, NY 1978, pp $53-69$.

10. Henschel A. The environment and performance. In: Simonson E, ed. Physiology of work capacity and fatigue. Charles $\mathrm{C}$ Thomas, Springfield, IL 1971, pp 325-347.

11. Hubbard RW. Effects of exercise in heat on predisposition to heatstroke. Med sci sports 11 (1979) 66-71.

12. Kenedi I. A hoemunkàsok szive. Iparegészséguegyi Koezlemények 1 (1948) 125145.

13. Kloetzel $\mathrm{K}$, de Andrade AE, Falleiros $\mathrm{J}$, Pacheco JC. Relationship between hypertension and prolonged exposure to heat. $J$ occup med 15 (1973) 878-880.

14. Knecht EA, Wright GL, Toraason MA. Periodic short-term heat exposure and reproductive function in male and female rats. Can $j$ physiol pharmacol 56 (1978) 747-753.

15. Lambert G. L'adaptation physiologique et psychologique de l'homme aux conditions de vie desertiques. Hermann, Paris 1968.

16. Leithead CS, Lind AR. Heat stress and heat disorders. FA Davis, Philadelphia, PA 1964.

17. Maffly RH. Running out of water. Emergency med 11 June (1979) 57-61.

18. Mayer-Theveniaud N. Les travaux en temperature elevee. Doctoral dissertation. Faculty of Medicine of Dijon, Dijon, 1977.

19. National Institute for Occupational Safety and Health. Criteria for a recommended standard... Occupational exposure to hot environments. Cincinnati, OH 1972. (HSM 72-10269).

20. OSHA Standards Advisory Committee on Heat Stress. Recommendations for a standard for work in hot environments. Draft no 5. January 9, 1974. Occup saf health rep (1974) 1050-1057.

21. Pepler RD. Performance and well-being in heat. In: Herzfeld CM, ed. Temperature, its measurement and control in science and industry. Volume 3, Part 3, Hardy $\mathrm{DH}$, ed, Biology and medicine. Reinhold, New York, NY 1963, pp 319-336.

22. Pepler RD. Psychological effects of heat. In: Leithead CS, Lind AR. Heat stress and heat disorders. FA Davis, Philadelphia, PA 1964, pp 237-253.

23. Redmond CK, Emes JJ, Mazumdar S, Magee PC, Kamon E. Mortality of steelworkers employed in hot jobs. Department of Health Education and Welfare, Cincinnati, OH 1977. (DHEW (NIOSH) publication no 77-219)

24. Redmond CK, Emes JJ, Mazumdar S, Magee PC, Kamon E. Mortality of steelworkers employed in hot jobs. $J$ environ pathol toxicol 2 (1979) 75-96.

25. Rowell LB, Brengelmann GL, Blackman JR, Twiss RD, Kusumi F. Splanchnic blood flow and metabolism in heat-stressed man. J appl physiol 24 (1968) 475-484.

26. Schwartz HG. Ueber die Beurteilung und Erhaltung der Arbeitsfaehigkeit bei der Beschaeftigung in hohen Temparaturen. Zentralbl Arbeitsmed Arbeitssch 18 (1968) $176-178$.

27. Stewart JM, Van Rensburg AJ. Heat stress limits for men working in the gold mining industry. J mine vent soc s afr 30 (1977): $4,85-98$.

28. Strydom NB. The prevention of heat stroke. In: Symposium on heat stroke. Proc mine med off assoc sa 46 (1966) 63-66.

29. Toraason MA, Knecht EA, Wright GL. Effect of heat exposure on in vitro intestinal transport and utilization of glucose in the rat. Can j physiol pharmacol 58 (1980) 424-428.

30. Weiner JS, Khogali M. A physiological body-cooling unit for treatment of heat stroke. Lancet 1 (1980) 507-509.

31. WHO Scientific Group. Health factors involved in working under conditions of heat stress. World Health Organization, Geneva 1969. (WHO tech rep ser no 412).

32. Wright G, Iams S, Knecht E. Resistance to heat stress in spontaneously hypertensive rat. Can j physiol pharmacol 55 (1977) 975-982.

33. Wyndham CH. A survey of research initiated by the chamber of mines into chemical aspects of heat stroke. In: Symposium on heat stroke. Proc mine med off assoc sa 46 (1966) 68-79.

34. Wyndham $\mathrm{CH}$, Allan AM, Bredell GAG, Andrew R. Assessing the heat stress and establishing the limits for work in a hot mine. $\mathrm{Br} \mathrm{j}$ ind med 24 (1967) 255-271. 